\title{
Program Surveillance in Women with Early Breast Cancer - Pro
}

\author{
Siegfried Seeber ${ }^{\mathrm{a}} \quad$ Anja Welt ${ }^{\mathrm{b}}$

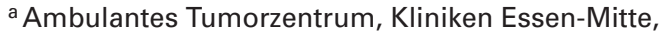 \\ ${ }^{\mathrm{b}}$ Innere Klinik und Poliklinik (Tumorforschung), Universitätsklinikum Essen, Germany
}

Two prospective randomised trials published in $1994[1,2]$ continue to be the basis of international guidelines, e.g. ASCO $[3,4]$ rejects regular laboratory tests and radiological / ultrasound screening procedures in the follow-up of early breast cancer patients. According to these guidelines, follow-ups should be focused on the breast. Only patients with possible tumour-related symptoms should be screened for metastatic disease. In this article, we will review the data of available surveillance studies which did not show an advantage for female patients with intensified follow-up, and discuss arguments for a systematic surveillance in breast cancer patients.

In the study published by Del Turco et al. in 1994 [1], X-ray of the chest and bone scan was used, in addition to standard procedures. However, neither ultrasound of the liver nor any laboratory tests were performed. In the trial published by the GIVIO investigators, ultrasound of the liver was performed once a year [2]. Both trials did not examine tumour markers (CEA, CA 15-3). Consequently, the experimental procedures of the two studies are not qualified as 'intensive surveillance'. Furthermore, approximately $10 \%$ of the patients in the GIVIO trial developed metastatic disease during a follow-up of 5 years [2]. This is much lower than the known percentage from epidemiologic data (ca. 40\%). The expected statistical death rate for the population in this study is $35 \%$ at 5 years [2]. However, the study results show 18 and $20 \%$ death rates in the control group and in the intensive group, respectively [2]. The lower death rates can be explained by the fact that both studies enrolled mainly patients with 'good-risk' profile, as can be seen by the absence of axillary lymph nodes in approximately $50 \%$ of the patients, and by the very small number of patients $(<10 \%)$ with pT3 or pT4 tumours at the time of diagnosis [1,2]. Therefore, it is not surprising that no differences in the survival rates had been observed in the two studies.

At the time the surveillance studies discussed above were published, many substances, such as taxanes, vinorelbin, capecitabine, aromatase inhibitors and trastuzumab, were not yet available. We have seen evidence that with the introduction of new effective drugs, the overall survival rate of patients with recurrent breast cancer has improved significantly over the past years [5-6]. The retrospective analysis conducted at the M.D. Anderson Institute in Texas [5] showed that 5-year overall survival rates in patients with recurrent breast cancer improved continuously, from 1974 (10\%) to 2000 (40\%). Similar results were reported for Canada [6]. Although these were retrospective investigations from individual clinics (which are, however, also world-wide leading institutes in this area), the results demonstrate significantly improved treatment possibilities, even in the case of metastatic illness. All of these suggest that cancer patients should be given adequate treatment with no fatalistic attitude to their diseases. There is no doubt that many of our patients really do profit from 3rd and 4th line treatments, and this experience is far from solely being 'casuistic'. The positive development in stage IV breast cancer is expected to continue even in times of restricted financial resources (e.g. bevacizumab, lapatinib, etc.). The limited therapeutic spectrum, as available when the studies cited above [1, 2] had been performed, remains a real problem and current guidelines should definitely not be based on such biased comparative analyses.

Treatment options are considerably limited in advanced diseases if symptoms such as dyspnoea or jaundice are already present at the initial diagnosis of metastatic disease: The associated deteriorated general condition of the patient, as well as elevated levels of GOT/GPT and bilirubin etc. are considered reliable indicators of an unfavourable prognosis. Patients with these symptoms are widely excluded from current study protocols. At the Tumour Centre in Essen, there are numerous cases of patients with inoperable liver metastasis who survived for more than 5 years [7, manuscript in preparation]. If their treatment had been started at the time when the first symp-

\begin{tabular}{|c|c|}
\hline KARGER & (C) 2007 S. Karger GmbH, Freiburg \\
\hline $\begin{array}{l}\text { Fax +49 } 7614520714 \\
\text { E-mail Information@Karger.de } \\
\text { www.karger.com }\end{array}$ & $\begin{array}{l}\text { Accessible online at: } \\
\text { www.karger.com/brc }\end{array}$ \\
\hline
\end{tabular}

Prof. Dr. med. Siegfried Seeber Ambulantes Tumorzentrum Kliniken Essen-Mitte

Henricistr. 40-42, 45136 Essen, Germany Tel. +49 201 174-1290, Fax -1293

E-mail s.seeber@kliniken-essen-mitte.de 
toms of visceral metastasis appeared, the patients would not have benefited fully from an individually adjusted optimal therapeutic sequence, which nowadays makes use of all available options.

Patients who could obtain a complete remission (CR) with chemotherapy have the best chance of long-term survival [8, 9]. A crucial prognosis factor to reaching $\mathrm{CR}$ is a small tumour load [8]. In the case of diffuse liver or lung metastasis, CR is only rarely attainable. Patients with the best chance of CR are also those with still limited asymptomatic metastasis. They might only be detected with follow-ups which allow imaging diagnostic procedures, even in the case of asymptomatic disease [10].

In the case of still localised metastasis, one option is surgical intervention, together with systemic therapies when necessary $[11,12]$. In terms of metastasis resection, by which a 'no evidence of disease' status can be achieved, there are only nonrandomised studies for metastatic breast cancer. Given that good results are reported after the resection of solitary visceral metastasis in colorectal cancer $[15,16]$, it is reasonable to draw an analogous conclusion. Even though there are no prospective randomised studies on the resection of metastasis of colorectal cancer, the results of non-randomised trials and retrospective analyses have been convincing enough that these measures are now included in the general treatment rec- ommendations $[17,18]$. Therefore, regular screening of chest and abdomen by CT scans is strongly recommended in surveillance of colorectal cancer patients $[17,18]$, because these asymptomatic metastases would otherwise not be detected. These localised therapies are in fact suitable for only a small number of patients. Since the treatments for metastatic breast cancer, according to general consensus, is an individual therapy, patients should not be deprived of these approaches that provide a chance of long-term survival.

Overall, symptom-guided follow-ups appear to be adequate for patients with small primary tumours and with no lymph node involvement, hence giving rise to a high probability of curative treatment. However, it is the authors' opinion that systematic surveillance should be recommended for high-risk patients even in the absence of symptoms. Furthermore, in addition to the recommended procedures in the current guidelines, surveillance should also include ultrasound of the liver, $\mathrm{X}$-ray of the chest and monitoring of the tumour markers CEA and CA 15-3 every 3 months. Bone scans appear to be dispensable, given that bone metastasis is usually noticeable at an early stage due to pain [19, 20]. All patients, however, should be fully informed of the possibility of metastatic disease development and be given the option to select the quality of their postoperative follow-ups.

\section{References}

1 Del Turco MR, Palli D, Cariddi A, et al.: Intensive diagnostic follow-up after treatment of primary breast cancer. A randomized trial. National Research Council Project on Breast Cancer FollowUp. JAMA 1994;271:1593-1597.

2 The GIVIO Investigators: Impact of follow-up testing on survival and health-related quality of life in breast cancer patients. JAMA 1994;271:1587-1592.

3 Khatcheressian JL, Wolff AC, Smith TJ, et al.: American Society of Clinical Oncology 2006 update of the breast cancer follow-up and management guidelines in de adjuvant setting. J Clin Oncol 2006;24:1-7.

4 Bast RC, Ravdin P, Hayes DF, et al.: 2000 update of recommendations for the use of tumor markers in breast and colorectal practice guidelines of the American Society of Clinical Oncology. J Clin Oncol 2001;19:1865-1878.

5 Giordano SH, Budzar AU, Smith TL, et al.: Is breast cancer survival improving? Trends in survival for patients with recurrent breast cancer diagnosed from 1974 through 2000. Cancer 2004;100: 44-52.

6 Chia SK, Speers C, Kang A et al.: The impact of new chemotherapeutical and hormonal agents on the survival of women with metastatic breast cancer $(\mathrm{MBC})$ in a population based cohort. Proc Am Soc Clin Oncol 2003;22:abstr 22.
7 Seeber S, Pohlkamp C, Welt A, et al.: Long-term survival with metastatic breast cancer: first results of a retrospective analysis of patients treated at the West German Cancer Center (University of Essen, medical school). 27. Deutscher Krebskongress Deutsche Krebsgesellschaft e.V. 2006, abstr. http:// www.egms.de/en/meetings/dkk2006/06dkk155.shtml \#

8 Greenberg P, Hortobagyi GN, Smith TL, et al.: Long-term follow-up of patients with complete remission following combination chemotherapy for metastatic breast cancer, J Clin Oncol 1996;14: 2197-2205.

9 Tomiak E, Piccart M, Mignolet F, et al.: Characterisation of complete responders to combination chemotherapy for advanced breast cancer: a retrospective EORTC Breast Group study. Eur J Cancer 1996;32A:1876-1887.

10 Hortobagyi GN: Can we cure limited metastatic breast cancer? J Clin Oncol 2002;20:620-623.

11 Nieto Y, Nawaz S, Jones RB, et al.: Prognostic model for relapse after high-dose chemotherapy with autologous stem-cell transplantation for stage IV oligometastatic breast cancer. J Clin Oncol 2002;20:707-718.

12 Bojko P, Welt A, Schleucher R, et al.: High-dose chemotherapy with autologous stem cell transplantation in patients with oligometastatic breast cancer. Bone Marrow Transplant 2004;34:637-643.

13 Elias D, Maisonnette F, Druet-Cabanac M, et al.: An attempt to clarify indications for hepatectomy for liver metastasis from metastatic breast cancer. Am J Surg 2003;185:158-164.
14 Pocard M, Pouillart P, Asselain B, et al.: Hepatic resection in metastatic breast cancer: results and prognostic factors. Eur J Surg Oncol 2000;26: 155-159.

15 Scheele J, Altendorf-Hofmann A, Grube T, et al.: Resektion colorectaler Lebermetastasen. Welche Prognosefaktoren bestimmen die Patientenselektion? Chirurg 2001;72:547-560.

16 Girad P, Baldeyrou P, Le Chevalier T, et al.: Surgery for pulmonary metastases. Who are the 10year survivors? Cancer 1994;74:2191-2197.

17 Desch CE, Benson AB III, Somerfield MR, et al.: Colorectal cancer surveillance: 2005 update an American Society of Clinical Oncology practice guidelines. J Clin Oncol 2005;23:8512-8519.

18 Junginger T, Lorenz W (eds): Diagnostik, Therapie und Nachsorge des Kolorektalen Karzinoms - Interdisziplinäre S3-Leitlinie der Deutschen Fachgesellschaften; 2004. http://www-klinik.uni-mainz.de/ Allgemchir/Leitlinienmanuskript.pdf

19 Burkett FE, Scanion EF, Garces R, et al.: The value of bone scans in the management of patients with carcinoma of the breast. Surg Gynocol Obstet 1979; 149:523-525.

20 Perez DJ, Powles TJ, Milan J, et al.: Detection of breast carcinoma metastases in bone: relative merits of X-rays and skeletal scintigraphy. Lancet 1983; 2:613-616. 